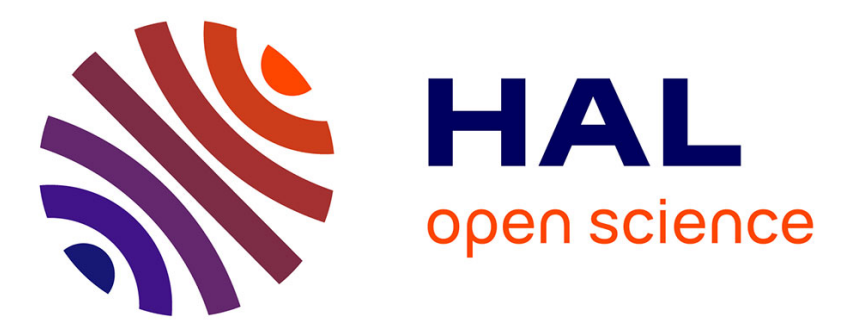

\title{
Co-adsorption and interaction mechanism of cadmium and sulfamethazine onto activated carbon surface
} Zisong Xu, Wenyu Huang, Hongjie Xie, Xiaoqing Feng, Shuangfei Wang, Hainong Song, Jianhua Xiong, Gilles Mailhot

\section{- To cite this version:}

Zisong Xu, Wenyu Huang, Hongjie Xie, Xiaoqing Feng, Shuangfei Wang, et al.. Coadsorption and interaction mechanism of cadmium and sulfamethazine onto activated carbon surface. Colloids and Surfaces A: Physicochemical and Engineering Aspects, 2021, 619, pp.126540. 10.1016/j.colsurfa.2021.126540 . hal-03194131

\section{HAL Id: hal-03194131 \\ https://hal.uca.fr/hal-03194131}

Submitted on 9 Apr 2021

HAL is a multi-disciplinary open access archive for the deposit and dissemination of scientific research documents, whether they are published or not. The documents may come from teaching and research institutions in France or abroad, or from public or private research centers.
L'archive ouverte pluridisciplinaire HAL, est destinée au dépôt et à la diffusion de documents scientifiques de niveau recherche, publiés ou non, émanant des établissements d'enseignement et de recherche français ou étrangers, des laboratoires publics ou privés.

\section{(ㅇ)(1) $\$$}

Distributed under a Creative Commons Attribution - NonCommercial - NoDerivatives 44.0 


\section{Co-adsorption and interaction mechanism of cadmium and}

\section{2 sulfamethazine onto activated carbon surface}

3

Zisong $\mathrm{Xu}^{\mathrm{a}}$, Wenyu Huang ${ }^{\mathrm{a}, c^{*}}$, Hongjie Xie ${ }^{\mathrm{a}}$, Xiaoqing Feng ${ }^{\mathrm{a}}$, Shuangfei Wang ${ }^{\mathrm{b}, \mathrm{c}}$, Hainong Song ${ }^{\mathrm{c}}$, Jianhua Xiong ${ }^{\mathrm{a}, \mathrm{c}}$, Gilles Mailhot ${ }^{\mathrm{d}}$

${ }^{a}$ School of Resources, Environment and Materials, Guangxi University, 100 Daxue East Road, Nanning 530004, China

${ }^{\mathrm{b}}$ School of Marine Science, Guangxi University, 100 Daxue East Road, Nanning 530004, China

${ }^{\mathrm{c}}$ Guangxi Bossco Environmental Protection Technology Co.,Ltd, Nanning 530007, China

${ }^{\mathrm{d}}$ Université Clermont Auvergne, CNRS, SIGMA Clermont, Institut de Chimie de Clermont-Ferrand, F-63000 Clermont-Ferrand, France

* Corresponding author: Wenyu Huang (huangwenyu@gxu.edu.cn)

\footnotetext{
ABSTRACT

Owing to their diverse functional groups, antibiotics can easily form complexes with heavy metals; the complexation alters the migration and transformation behavior of both antibiotics and heavy metals. In this study, we investigated the co-adsorption mechanism of sulfamethazine (SMT) and cadmium $\left(\mathrm{Cd}^{2+}\right)$ heavy metal ions and created an ideal water model containing two major contaminants: sulfamethazine and heavy metal cadmium ions. Combined with the experimental analysis of the interaction mechanism, the results
} 
indicate the heterogeneous multilayer adsorption of SMT on the surface of activated carbon (AC). The bridging role of cadmium ions promotes the adsorption of SMT through the formation of SMT- $\mathrm{Cd}^{2+}-\mathrm{AC}$ ternary complexes on the surface of activated carbon. Characterization experiments provided further insight into the adsorption behavior of $\mathrm{Cd}^{2+}$ and SMT on activated carbon, revealing a strong correlation between the $\mathrm{Cd}^{2+}$-SMT complexation and the SMT adsorption capacity. These results indicate that the effects of the coexistence of antibiotics and heavy metal ions should be fully taken into account when investigating the environmental behavior of antibiotics and heavy metal ions.

Key words: Heavy Metal, Antibiotics, Bridging, Complexation, Adsorption

\section{Introduction}

Fast industrialization and growing social activities result in the composition of wastewater becoming increasingly more complex[1]. The combined pollution by antibiotics and heavy metals, widely affecting actual water systems, is causing widespread concern[2, $\underline{3}$. These two pollutants can cause serious harm to humans and ecosystems[]. The use of antibacterial agents in the livestock and poultry breeding industry, the land use of livestock and poultry manure, and the centralized treatment of industrial wastewater have led to increasingly serious pollution in surface water or groundwater[]ㅡ. Sulfanilamide antibiotics and cadmium heavy metals are the most typical co-pollutants in livestock and poultry breeding industries[므, 7]. Cadmium mainly originates from excessive use of Cd-containing chemicals (insecticides and fungicides) as well as cadmium-rich feces[]․ Cadmium fertilizers are employed in domestic poultry breeding[ㅁ] . Synthetic antibiotics have been used in livestock feed to improve feed efficiency and promote growth[1]. However, 
foreign antibiotics are usually difficult to be absorbed by animals, and are directly discharged into the receiving waters, where they may pose a serious threat to organisms and trigger antibiotic resistance[10]. Therefore, the efficient removal of antibiotics has attracted worldwide attention[11]. More importantly, antibiotics can form complexes with coexisting metal ions[11-13], which may significantly alter their chemical properties, migration/transformation process, and ecotoxic reactions[14]. For instance, it has been reported that chelation with antacids (magnesium or aluminum salts) will change the bioavailability of quinolones. Therefore, in environments co-polluted with heavy metal ions, complexation may have unexpected environmental consequences[토] .

Adsorption methods are the key approaches to study the transfer and transformation of pollutants in the environment. Compared with coagulation, filtration, advanced oxidation, and other methods, the flexible design/operation and low energy consumption of adsorption processes make them the preferred approach for the practical production of clean water from wastewater, with high removal efficiency and less toxic by-products. In addition, this green technology produces no sludge and is compatible with other water treatment systems $[\underline{16}, \underline{17}]$. Many groups are currently investigating the treatment of antibiotics and heavy metals using adsorption methods. It has been reported that graphene oxide and ordered mesoporous carbon materials with high adsorption capacity can effectively remove ciprofloxacin (CIP) pollutants in water $\underline{18}$, 19]. Li et al.[20] prepared a biochar sample that was used to remove tetracycline and sulfadiazine. In addition, many detailed studies have focused on the removal of $\mathrm{Cu}^{2+}, \mathrm{Pb}^{2+}[\underline{21}], \mathrm{Hg}^{2+}[\underline{22}], \mathrm{Cr}(\mathrm{VI})[\underline{23}]$, and $\mathrm{Cd}^{2+}[\underline{24}]$ from water using carbon-based materials.

The combination of antibiotics and heavy metals has become a new component of polluted water. Present research on the adsorption of single heavy metals or antibiotics does not reflect the current state of environmental pollution. Relevant studies have shown that the presence of heavy metals can promote or 
inhibit the adsorption process of different antibiotics, depending on the type and concentration of heavy metals[25]. $\mathrm{Na}[26]$ and co-workers focused on two antibiotics commonly used in aqueous environments (tetracycline hydrochloride and sulfadiazine) and two typical heavy metals (copper and zinc). Their results showed that when antibiotics coexist with heavy metals in water, they can form complexes through complexation. The cations of multivalent heavy metals can significantly enhance the adsorption of antibiotics through the bridging effect[27-29]. For example, $\mathrm{Cu}(\mathrm{II})$ can improve the adsorption capacity. The formation of $\mathrm{CIP}-\mathrm{Cu}(\mathrm{II})$ complexes at $\mathrm{pH}$ values above 6.0 was simulated by surface complexation on goethite[27]. The presence of $\mathrm{Ni}(\mathrm{II})$ promoted the adsorption of CIP on activated carbon (AC)[29]. The mechanism by which metal ion complexation affects antibiotic adsorption is extremely complex. Although some reports on the co-adsorption behavior of composite antibiotics and metal pollutants are available, studies on the influence of metal ions on the adsorption of antibiotics are still scarce. In particular, the mechanism of co-adsorption has not been investigated in sufficient detail. However, our understanding of the mechanism controlling the influence of metal ions on the adsorption of antibiotics is still limited. At present, the main metal ions involved in these studies are $\mathrm{K}^{+}, \mathrm{Na}^{+}, \mathrm{Ca}^{2+}, \mathrm{Mg}^{2+}, \mathrm{Cu}^{2+}, \mathrm{Ni}^{2+}$, and $\mathrm{Fe}^{3+}$, whereas only few investigations have focused on toxic heavy metal ions such as $\mathrm{Cr}^{6+}$ and $\mathrm{Cd}^{2+}[\underline{30]}$. The microscopic characterization of the interaction between metal ions and antibiotics and of the mechanism by which metal ion complexation affects antibiotic adsorption is still insufficient. Activated carbon has advantages such as stable chemical properties, strong adsorption capacity, low cost, and wide availability. Therefore, the study of the interfacial adsorption behavior of multiple pollutants on activated carbon will support the design of cost-effective adsorbents $[\underline{31}, \underline{32}]$. For this purpose, it is necessary to explore the co-adsorption and interaction mechanism of antibiotics and heavy metals on the surface of activated carbon. 
metals (cadmium) in single and binary contaminated solutions, and created an ideal water model containing two major contaminants: sulfamethazine and heavy metal cadmium ions. The influence of other ions in the natural environment was ignored temporarily. To more clearly observe the influence of cadmium ion on the adsorption capacity of SMT and the influence of complexation on the adsorption, and to observe the changes on the surface and inside of the adsorbent after adsorption in a short time, a relatively large concentration range of SMT and $\mathrm{Cd}^{2+}$ was adopted in this study. First, we studied the adsorption behaviors of sulfamethazine and cadmium ions on activated carbon in single and binary systems, based on the analysis of adsorption kinetics and isotherms. Then, X-ray photoelectron spectroscopy (XPS), Raman, nuclear magnetic resonance, and Fourier transform infrared (FTIR) spectroscopy techniques were used to characterize adsorption changes in the binary system and the correlation between the complexation and the adsorption amount. The analysis of the characterization and adsorption mechanism results allowed elucidating the influence of complexation on the adsorption process, providing a comprehensive description of the adsorption and interaction mechanism in the binary system.

\section{Materials and methods}

\subsection{Materials} respectively. All reagents used in this study were of analytical grade and used without further purification. 

studied the effects of these parameters on the adsorption. In the experiment, $20 \mathrm{mg}$ activated carbon was used in a $150 \mathrm{~mL}$ test solution with a constant initial SMT concentration $\left(25 \mathrm{mg} \cdot \mathrm{L}^{-1}\right)$ and sufficient contact time $(24 \mathrm{~h})$ at $303 \mathrm{~K}$. A conical flask ( $250 \mathrm{~mL}$, glass) was shaken with a water bath thermostatic oscillator at $200 \mathrm{rpm}$. Samples were collected at different time intervals, and an UV-Vis spectrophotometer was used to scan the whole UV region and determine the adsorption equilibrium time of SMT. The dosage of activated carbon was set to $5,10,20,30$, and $40 \mathrm{mg}$ in a $150 \mathrm{~mL}$ test solution with constant initial antibiotic concentration $\left(25 \mathrm{mg} \cdot \mathrm{L}^{-1}\right)$ and adsorption equilibrium time $(12 \mathrm{~h})$, in order to determine the optimal dosage of adsorbent. In the experiment, $20 \mathrm{mg}$ activated carbon was used in a $150 \mathrm{~mL}$ test solution with a constant initial $\mathrm{Cd}^{2+}$ concentration $\left(25 \mathrm{mg} \cdot \mathrm{L}^{-1}\right)$ and sufficient contact time $(24 \mathrm{~h})$ at $303 \mathrm{~K}$. A conical flask $(250 \mathrm{~mL}$, glass) was shaken with a water bath thermostatic oscillator at $200 \mathrm{rpm}$. Samples were collected at different time intervals, and inductively coupled plasma-atomic emission spectrometry(ICP-AES) was used to determine the adsorption equilibrium time of $\mathrm{Cd}^{2+}$. We investigated the adsorption behavior of SMT and $\mathrm{Cd}^{2+}$ at different temperatures and carried out adsorption isotherm measurements. The temperature was set to 303,313 , and $323 \mathrm{~K}$, and the water bath was shaken at $200 \mathrm{rpm}$ under the above optimal conditions. We 

ratio of 1:1 between antibiotic and cadmium ions. The adsorption isotherm experiments were carried out at three different temperatures $(303,313,323 \mathrm{~K})$. the chemical shifts of surface elements of SMT before and after adding $\mathrm{Cd}^{2+}$. 

was measured using deionized water as blank control, at a SMT maximum absorption wavelength of $261 \mathrm{~nm}$. spectrometry (ICP-AES). adsorption, respectively, while $V(\mathrm{~mL})$ and $M(\mathrm{mg})$ are the added volume of SMT or cadmium ion solutions and the mass of activated carbon, respectively. adsorption isotherms of SMT and $\mathrm{Cd}^{2+}$ to evaluate the distribution of SMT and $\mathrm{Cd}^{2+}$ in the solid phase and 
where $\mathrm{q}_{\max }\left(\mathrm{mg} \cdot \mathrm{g}^{-1}\right)$ is the maximum adsorption concentration of SMT and $\mathrm{Cd}^{2+}$ per unit mass of AC.

$\mathrm{K}_{\mathrm{L}}\left(\mathrm{L} \cdot \mathrm{mg}^{-1}\right)$ and $\mathrm{K}_{\mathrm{F}}\left(\mathrm{L} \cdot \mathrm{mg}^{-1}\right)$ are respectively the adsorption constant of Langmuir and Freundlich models.

SMT adsorption capacity can thus be determined[ $\underline{36}, \underline{37}]$.

\section{Results and discussion}

amphoteric compound, SMT presents different proton states $\left(\mathrm{SMT}^{+}, \mathrm{SMT}^{-}\right.$, and $\left.\mathrm{SMT}\right)$ at different $\mathrm{pH}$ 
Fig. 1c. The $\mathrm{Cd}^{2+}$ adsorption equilibrium was reached at approximately $2 \mathrm{~h}$. The results of this study are generally consistent with previous reports (Figs. 1a and 1c) $[\underline{18}, \underline{19}, \underline{38]}$. Meanwhile, this study focuses on the effect of cadmium ions on the adsorption capacity of SMT, to accurately approach the typical pH value of an actual water body containing SMT contaminant $(\mathrm{pH}=7)$, the single adsorption experiment of cadmium ion and the subsequent experiments of this study were carried out under the condition of $\mathrm{pH}=7[\underline{40}, \underline{41}]$. on the SMT adsorption was investigated by adding different amounts of AC to the solution. The results show that the removal rate of SMT increased from $46.2 \%$ to $99.1 \%$ as the AC dosage increased from 33.33 to $266.67 \mathrm{mg} \cdot \mathrm{L}^{-1}$, due to the increased number of adsorption sites on the adsorbent surface. When he amount of $\mathrm{AC}$ was further increased, the removal rate of SMT remained almost unchanged, due to the decrease in the adsorption capacity per unit mass of adsorbent. At higher adsorbent concentrations, the effective surface area decreases, and the aggregation or overlap between adsorption sites leads to a decrease in the available adsorbent surface area and an increase in diffusion path length. Some of the examined adsorbent systems fail 

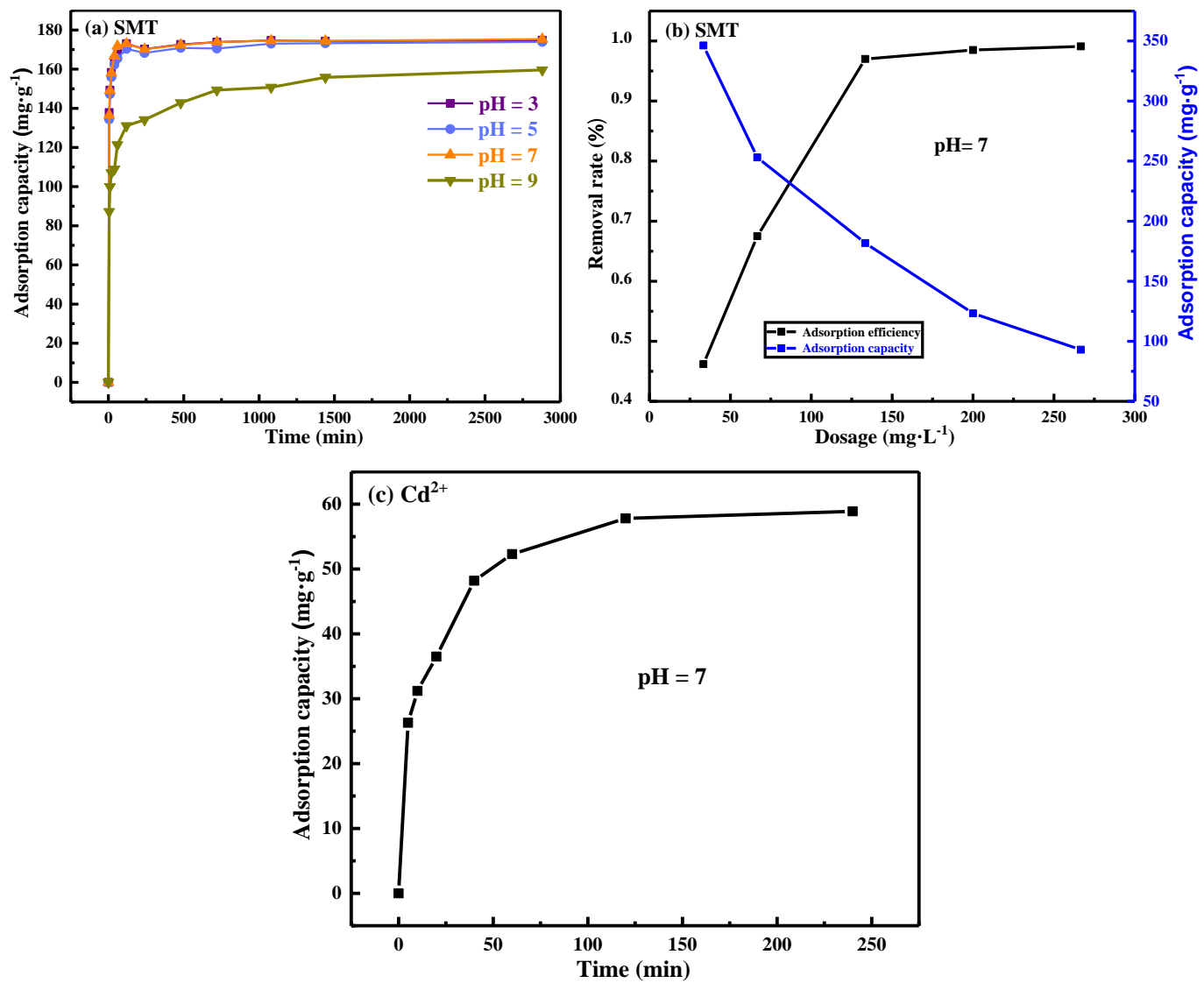

Fig. 1. Effect of contact time (a) and adsorbent dosage (b) on adsorption of SMT; (c) effect of contact time on adsorption of $\mathrm{Cd}(\mathrm{I})$. antibiotics and heavy metals showed a significantly different adsorption behavior. As shown in Fig. 2, at a solution $\mathrm{pH}$ of 7 , when the cadmium ion concentration increased from 0 to $650 \mathrm{mg} \cdot \mathrm{L}^{-1}$, the synergistic effect of $\mathrm{Cd}^{2+}$ promoted the SMT adsorption on AC. Previous reports speculated that heavy metals acting as electron acceptors have the ability to form $\mathrm{Cd}^{2+}$-SMT complexes by coordination and electrostatic adsorption, providing more adsorption sites for SMT in water, thus promoting the adsorption process [333, $\underline{42}]$. 


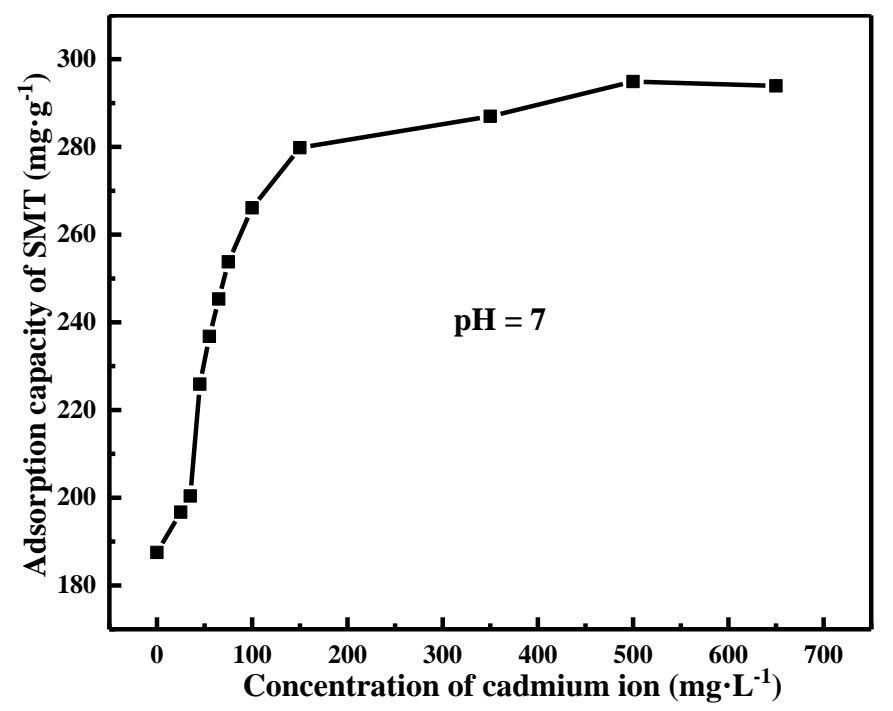

Fig. 2. Effect of cadmium ion concentration on adsorption of SMT.

Figs. 3a and 3b show the adsorption isotherms of SMT in the single and binary systems, respectively.

The Freundlich model was more suitable for SMT adsorption $\left(\mathrm{R}^{2}=0.959 / 0.982 / 0.954\right.$ for SMT with $\mathrm{Cd}^{2+}$, and $0.61 / 0.145 / 0.485$ without $\left.\mathrm{Cd}^{2+}\right)$ than the Langmuir model $\left(\mathrm{R}^{2}=0.942 / 0.94 / 0.949\right.$ for SMT with $\mathrm{Cd}^{2+}$, and 0.932/0.896/0.903 without $\mathrm{Cd}^{2+}$ ), which can be described as heterogeneous multilayer adsorption (Table 1).

Compared with the system without $\mathrm{Cd}^{2+}$, the presence of $\mathrm{Cd}^{2+}$ increased the adsorption capacity of SMT on activated carbon. In particular, the addition of $\mathrm{Cd}^{2+}$ significantly promoted the adsorption of SMT on activated carbon, which is consistent with the results of Fig. 2a. Relevant studies have shown that organic ligands bound with heavy metals can interact with functional groups on the surface of activated carbon to form stable complexes[43]. Higher numbers of electron-rich groups such as $\mathrm{N}$ and $\mathrm{O}$ in antibiotics lead to a stronger complexation ability with metal ions. Therefore, it can be further speculated that the organic ligands bound to cadmium ions may undergo complexation reactions with the functional groups on the surface of activated carbon, even though the numbers and types of different functional groups in sulfonamides are limited, and the N-containing functional groups are mainly involved in the coordination[ㄴ4]. The study has shown that bridging by metal centers is one of the most important mechanisms for the adsorption of 
antibiotics on adsorbents[26]; this may explain how $\mathrm{Cd}^{2+}$ can promote the adsorption of SMT on activated

248 carbon, which will be further confirmed by the experiments described in the following.

Table 1 Calculated Langmuir and Freundlich parameters of SMT adsorption isotherms

\begin{tabular}{|c|c|c|c|c|c|c|c|}
\hline \multirow[t]{2}{*}{ Models } & \multirow[t]{2}{*}{ Parameters } & \multicolumn{3}{|c|}{ SMT } & \multicolumn{3}{|c|}{ SMT(complex) } \\
\hline & & $303 \mathrm{~K}$ & $313 \mathrm{~K}$ & $323 \mathrm{~K}$ & $303 \mathrm{~K}$ & $313 \mathrm{~K}$ & $323 \mathrm{~K}$ \\
\hline \multirow[t]{3}{*}{ Langmuir } & $\mathrm{q}_{\max }\left(\mathrm{mg} \cdot \mathrm{g}^{-1}\right)$ & 216.3 & 215.4 & 201.9 & 266.304 & 257.462 & 253.772 \\
\hline & $\mathrm{K}_{\mathrm{L}}\left(\mathrm{L} \cdot \mathrm{mg}^{-1}\right)$ & 3.191 & 9.062 & 2.383 & 1.131 & 1.479 & 1.375 \\
\hline & $\mathrm{R}^{2}$ & 0.61 & 0.145 & 0.485 & 0.922 & 0.92 & 0.919 \\
\hline \multirow[t]{3}{*}{ Freundlich } & $\mathrm{K}_{\mathrm{F}}\left(\mathrm{L} \cdot \mathrm{mg}^{-1}\right)$ & 8.329 & 9.069 & 9.235 & 8.732 & 7.219 & 6.251 \\
\hline & $\mathrm{n}$ & 0.665 & 0.716 & 0.793 & 0.699 & 0.809 & 0.803 \\
\hline & $\mathrm{R}^{2}$ & 0.979 & 0.929 & 0.919 & 0.959 & 0.982 & 0.954 \\
\hline
\end{tabular}
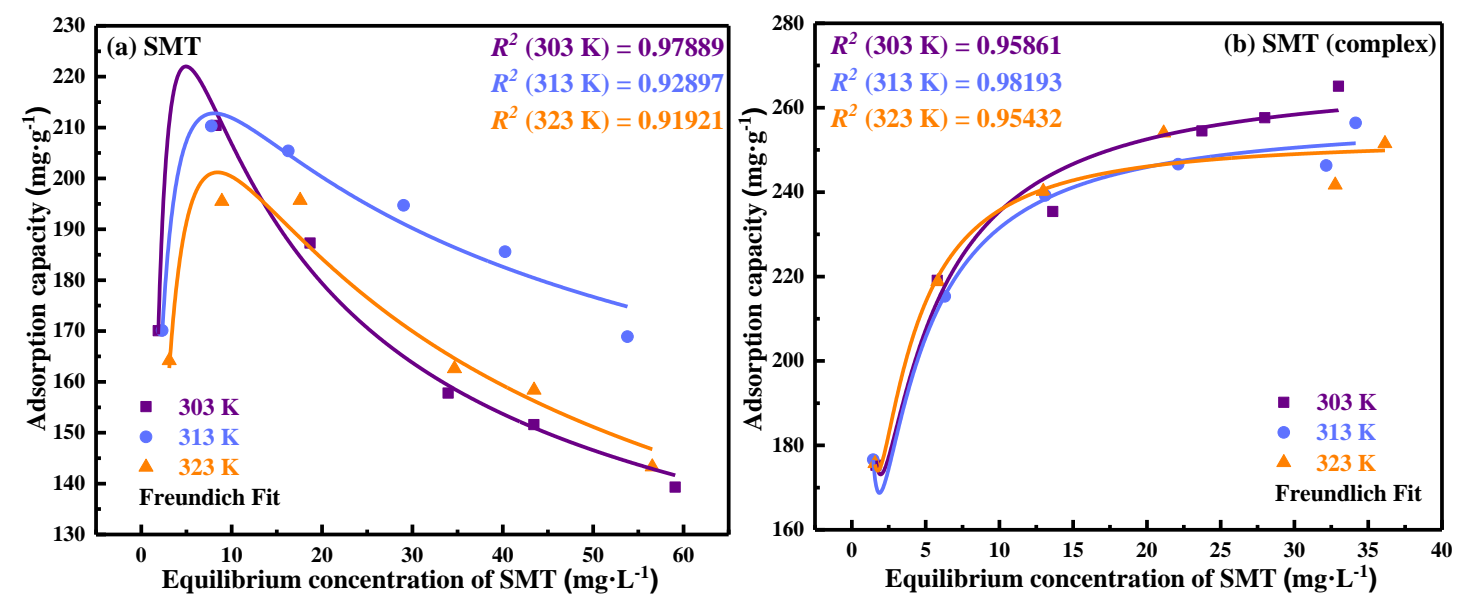

Fig. 3. Adsorption isotherms of SMT in single (a) and binary (b) systems, along with Freundlich model fits.

Figs. $4 \mathrm{a}$ and $4 \mathrm{~b}$ show the adsorption isotherms of $\mathrm{Cd}^{2+}$ in the single and binary system, respectively.

255 The adsorption amount of $\mathrm{Cd}^{2+}$ decreased after SMT was added to the system. This can be explained by assuming that the adsorption of $\mathrm{Cd}^{2+}$ was inhibited by the complexation with SMT, which thus reduced the 
adsorbed $\mathrm{Cd}^{2+}$ amount. The addition of cadmium ions initially promoted the adsorption of SMT; however,

258 when the $\mathrm{Cd}^{2+}$ concentration was further increased, no further increase in SMT adsorption was observed.

259 This suggests a monolayer adsorption behavior of cadmium ions on activated carbon, which cannot further

260 promote the adsorption of SMT at higher $\mathrm{Cd}^{2+}$ concentrations[25]. The Langmuir model was more suitable

261 for $\mathrm{Cd}^{2+}$ adsorption $\left(\mathrm{R}^{2}=0.959 / 0.999 / 0.966\right.$ for $\mathrm{Cd}^{2+}$ with $\mathrm{SMT}$, and $0.985 / 0.989 / 0.991$ without $\left.\mathrm{SMT}\right)$ than

262 the Freundlich model $\left(\mathrm{R}^{2}=0.932 / 0.926 / 0.903\right.$ for $\mathrm{Cd}^{2+}$ with SMT, and $0.932 / 0.896 / 0.903$ without

263 SMT)(Table 2). When the atomic sites on the surface of activated carbon are unsaturated, $\mathrm{Cd}^{2+}$ will be

264 adsorbed on the surface. After the adsorption of one layer of $\mathrm{Cd}^{2+}$ ions, the original unsaturated sites become

265 saturated, and no further adsorption on the activated carbon is possible. Due to the strong interaction

266 between the functional groups on the surface of activated carbon and $\mathrm{Cd}^{2+}$, the adsorption of the latter tends

267 to be uniform, resulting in a single-layer covering. This is consistent with the Langmuir isotherm model of monolayer adsorption[프].

Table 2 Calculated Langmuir and Freundlich parameters of $\mathrm{Cd}^{2+}$ adsorption isotherms

\begin{tabular}{|c|c|c|c|c|c|c|c|}
\hline \multirow[t]{2}{*}{ Models } & \multirow[t]{2}{*}{ Parameters } & \multicolumn{3}{|l|}{$\mathrm{Cd}^{2+}$} & \multicolumn{3}{|c|}{$\mathrm{Cd}^{2+}($ complex $)$} \\
\hline & & $303 \mathrm{~K}$ & $313 \mathrm{~K}$ & $323 \mathrm{~K}$ & $303 \mathrm{~K}$ & $313 \mathrm{~K}$ & $323 \mathrm{~K}$ \\
\hline \multirow[t]{3}{*}{ Langmuir } & $\mathrm{q}_{\max }\left(\mathrm{mg} \cdot \mathrm{g}^{-1}\right)$ & 59.6 & 88.55 & 81.2 & 32.744 & 22.036 & 36.455 \\
\hline & $\mathrm{K}_{\mathrm{L}}\left(\mathrm{L} \cdot \mathrm{mg}^{-1}\right)$ & 0.216 & 0.318 & 0.497 & 0.315 & 0.357 & 0.418 \\
\hline & $\mathrm{R}^{2}$ & 0.985 & 0.989 & 0.991 & 0.959 & 0.999 & 0.966 \\
\hline \multirow[t]{3}{*}{ Freundlich } & $\mathrm{K}_{\mathrm{F}}\left(\mathrm{L} \cdot \mathrm{mg}^{-1}\right)$ & 2.528 & 2.324 & 2.084 & 2.098 & 2.097 & 2.098 \\
\hline & $\mathrm{n}$ & 0.464 & 0.421 & 0.452 & 0.451 & 0.453 & 0.469 \\
\hline & $\mathrm{R}^{2}$ & 0.932 & 0.896 & 0.903 & 0.932 & 0.926 & 0.903 \\
\hline
\end{tabular}



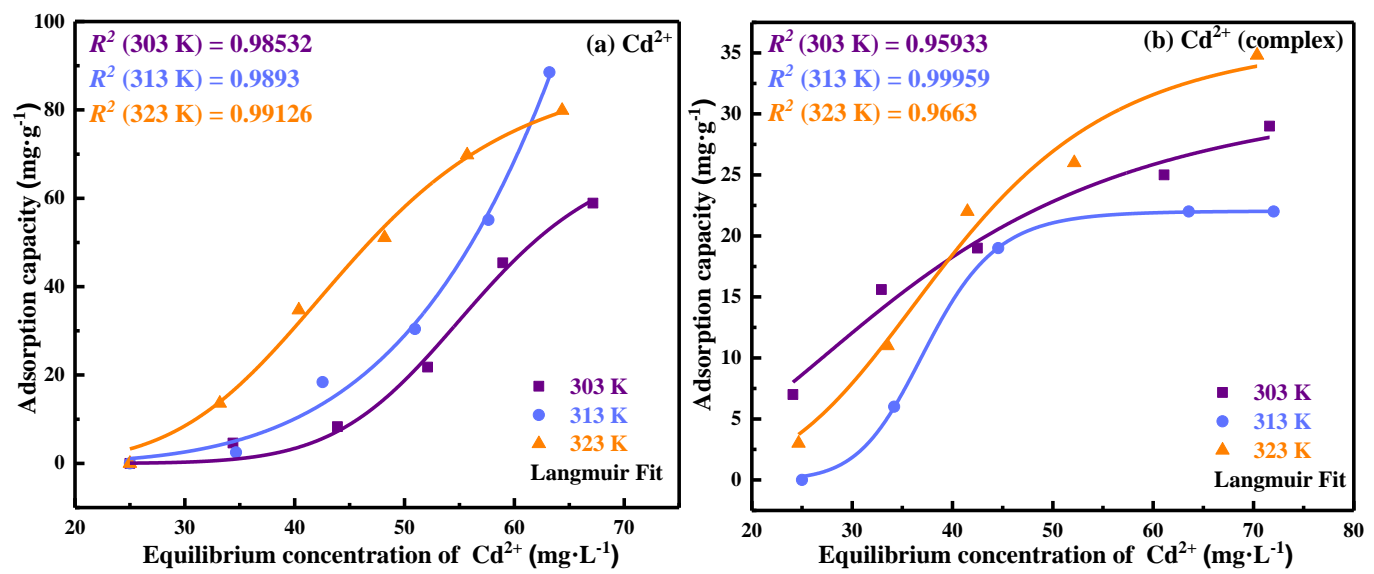

Fig. 4. Adsorption isotherms of $\mathrm{Cd}(\mathbb{I})$ in single (a) and binary (b) systems, along with Langmuir model fits.

3.3 Effect of complexation on co-adsorption

3.3.1 FTIR analysis of adsorption mechanism

adsorption. And the FTIR spectra of $\mathrm{Cd}^{2+}$, SMT and SMT $+\mathrm{Cd}^{2+}$ adsorbed on activated carbon were 
peak for the adsorption of heavy metal $\mathrm{Cd}^{2+}[\underline{49}]$. Under neutral conditions, SMT mainly exists in the form

290 of $\mathrm{SMT}^{0}$ and $\mathrm{SMT}^{-}[\underline{50}]$. When $\mathrm{Cd}^{2+}$ was added, the $\mathrm{H}$ part on the Sulfonamide group is ionized to form a

291 negatively charged SMT, which can be complexed with $\mathrm{Cd}^{2+}$ by replacing $\mathrm{H}^{+}[\underline{51}, \underline{52}]$. Therefore, in the

292 spectrum d (Fig. 5), the significant fluctuations at $3234 \mathrm{~cm}^{-1}-3445 \mathrm{~cm}^{-1}$ indicated that it is the vibration and

293 fracture of $-\mathrm{NH}$ in SMT, which complexes with $\mathrm{Cd}^{2+}$ by substituting $\mathrm{H}$ at the $\mathrm{N}$ atom[53]. After $\mathrm{Cd}^{2+}$ was

294 adsorbed on AC, new characteristic peaks appeared at $2937 \mathrm{~cm}^{-1}$ and $2866 \mathrm{~cm}^{-1}$, and this change was still

295 observed in AC-Cd ${ }^{2+}-\mathrm{SMT}$ samples, indicating the formation of AC-Cd ${ }^{2+}$-SMT ternary complex [49]. At the

296 same time, the outermost shell of the $\mathrm{Cd}^{2+}$ nucleus had an empty orbital that can accommodate lone pair

297 electrons, while oxygen, sulfur, nitrogen, and other atoms are typical lone pair electron donors [ $\underline{54}$ ]. It can be

298 speculated that the $\mathrm{N}$ atoms in the pyrimidine ring participate in the complexation process. The analysis of

299 the structure of the SMT molecule suggested that multiple interactions can be involved in the complexation

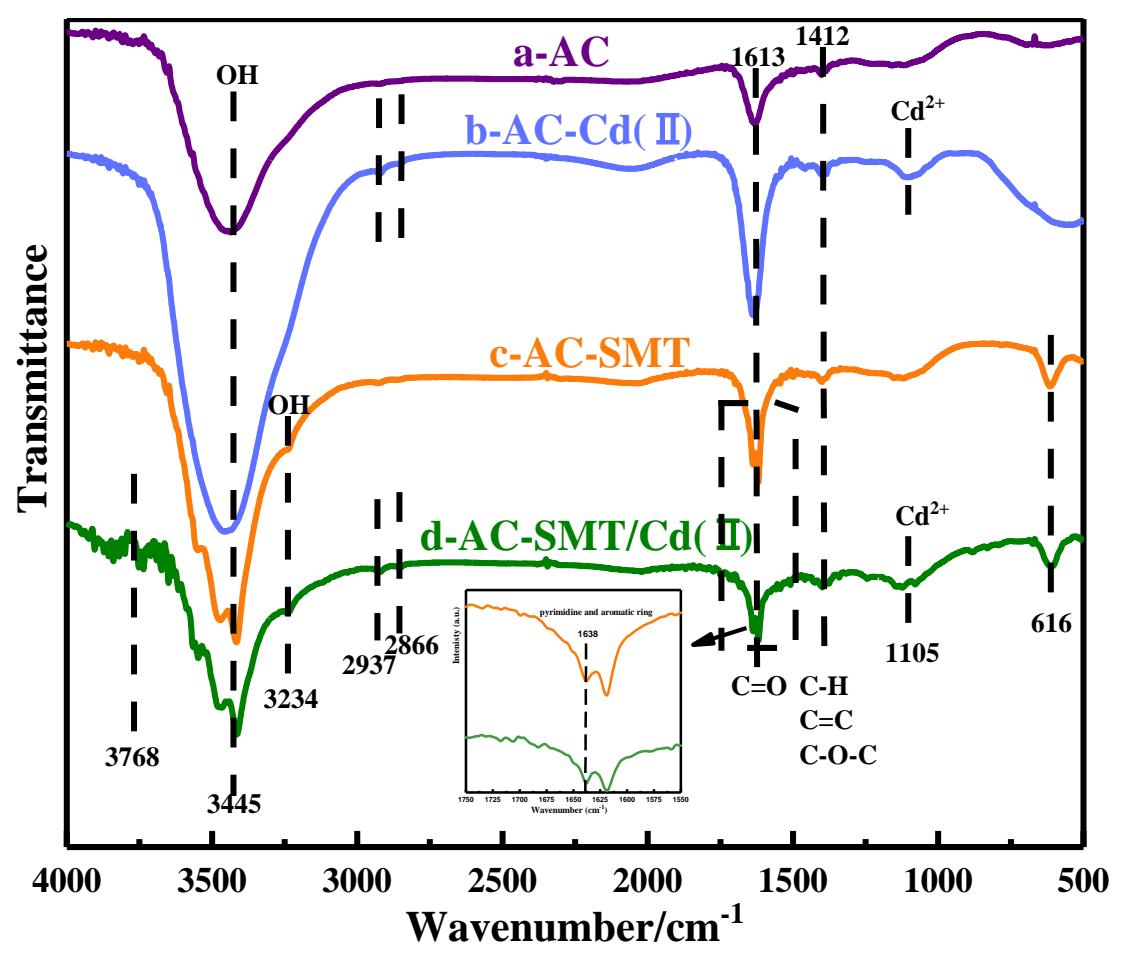

302 Fig. 5. FTIR spectra of (a) AC before adsorption, (b) Cd( I)-adsorbed AC, (c) SMT-adsorbed AC, and (d) 


\section{Table 3}

Elemental composition of AC, SMT-adsorbed AC, Cd( I)-adsorbed AC, and SMT/Cd( I)-adsorbed AC

\begin{tabular}{|c|c|c|c|c|c|}
\hline \multirow[t]{2}{*}{ Name } & \multicolumn{5}{|c|}{ Elemental analysis (atom based) $(\%)$} \\
\hline & $\mathrm{C}$ & $\mathrm{O}$ & $\mathrm{N}$ & $\mathrm{S}$ & $\mathrm{Cd}$ \\
\hline $\mathrm{AC}$ & 91.89 & 7.41 & 0.7 & a & a \\
\hline AC-SMT & 85.89 & 8.79 & 4.29 & 1.03 & a \\
\hline $\mathrm{AC}-\mathrm{Cd}(\mathrm{II})$ & 92.09 & 6.93 & 0.85 & a & 0.13 \\
\hline AC-Cd( II)-SMT & 84.38 & 7.7 & 5.81 & 1.97 & 0.15 \\
\hline
\end{tabular}

Table 1 shows a percentage of $\mathrm{Cd}(\mathrm{II})$ compared with the AC sample, indicating that $\mathrm{Cd}$ metal ions were adsorbed on the adsorbent surface. The adsorption of $\mathrm{Cd}^{2+}$ mainly relied on the electrostatic attraction

314 between $\mathrm{AC}$ surface and $\mathrm{Cd}^{2+}$ due to deprotonation[33], which proves that there was some kind of binding

315 interaction between them. SMT co-adsorption led to the simultaneous appearance of N1s and S2p peaks, as

316 shown in Fig. 6a. Compared with the AC sample, the $\mathrm{N}$ content in the AC-SMT system was significantly

317 higher, confirming that SMT was adsorbed on the surface. The $\mathrm{N}$ content further increased in the ternary 318 system, which indicates that the presence of $\mathrm{Cd}^{2+}$ promotes the adsorption of SMT. Cadmium ions are first 
adsorbed by cation- $\pi$ interactions and then diffuse to other adsorption sites. Although the cation- $\pi$ interaction does not promote the adsorption of SMT, cadmium species adsorbed at other sites may form SMT-Cd ${ }^{2+}$-AC complexes with negatively charged SMT, and $\mathrm{Cd}^{2+}$ ions at a certain concentration can enhance the adsorption of SMT[ㄷ5].

The N1s peak decomposes into two related peaks: $\mathrm{N}-\mathrm{C}=\mathrm{N}(399.3 \mathrm{eV})$ and $-\mathrm{NH}(400.6 \mathrm{eV})($ Figs.5b and 5c) [56]. According to the peak area calculation of Fig.5b and Fig.5c, it can be concluded that the -NH part of the system is reduced (the peak area is reduced from 1307.15 to 1198.3 ) with the addition of $\mathrm{Cd}^{2+}$. Moreover, the binding energy of $-\mathrm{NH}$ shifted from $400.6 \mathrm{eV}$ to $400.71 \mathrm{eV}$, while that of $\mathrm{N}-\mathrm{C}=\mathrm{N}$ shifted from $399.3 \mathrm{eV}$ to $399.24 \mathrm{eV}$. It is revealed that $\mathrm{-NH}$ in $\mathrm{SMT}$ is the main functional group involved in complexation, and $\mathrm{N}$ on the pyrimidine ring may also participate in complexation [49].

As shown in Fig. 6d, the binding energies of $\mathrm{Cd}(\mathrm{II})$ adsorbed in the binary system were shifted to lower values, showing that the changes in chemical bonding after adsorption on AC in the binary system resulted in a red shift of the XPS signals relative to those of the single heavy metal system. This means that the metal ions are in their reduced state in the presence of SMT[33]; the electrons involved in the reduction process are generated from the breaking of the N-H bond of SMT, which indicates that the metal cations interact with the $\mathrm{N}$ atoms (acting as electron donors) to form a complex after the N-H bond cleavage (Figs. $5 \mathrm{~b}$ and $5 \mathrm{c}$ ). This is consistent with the previous FTIR spectroscopy results. The atomic percentages obtained from the peak areas show that the metal ions enhanced the adsorption of SMT (from $4.29 \%$ to 5.81\%; Table 3), which is consistent with the adsorption isotherm experiments obtained for the SMT-Cd ${ }^{2+}$ system (Fig.3b). Therefore, at a certain concentration of $\mathrm{Cd}^{2+}$, the $\mathrm{AC}-\mathrm{Cd}^{2+}-\mathrm{SMT}$ ternary complex is formed through metal cation bridging. The cadmium ion acts as a bridge, indirectly connecting SMT with the adsorbent[57]. In the absence of cadmium ions, the surface functional groups of SMT molecules and adsorbents are negatively 

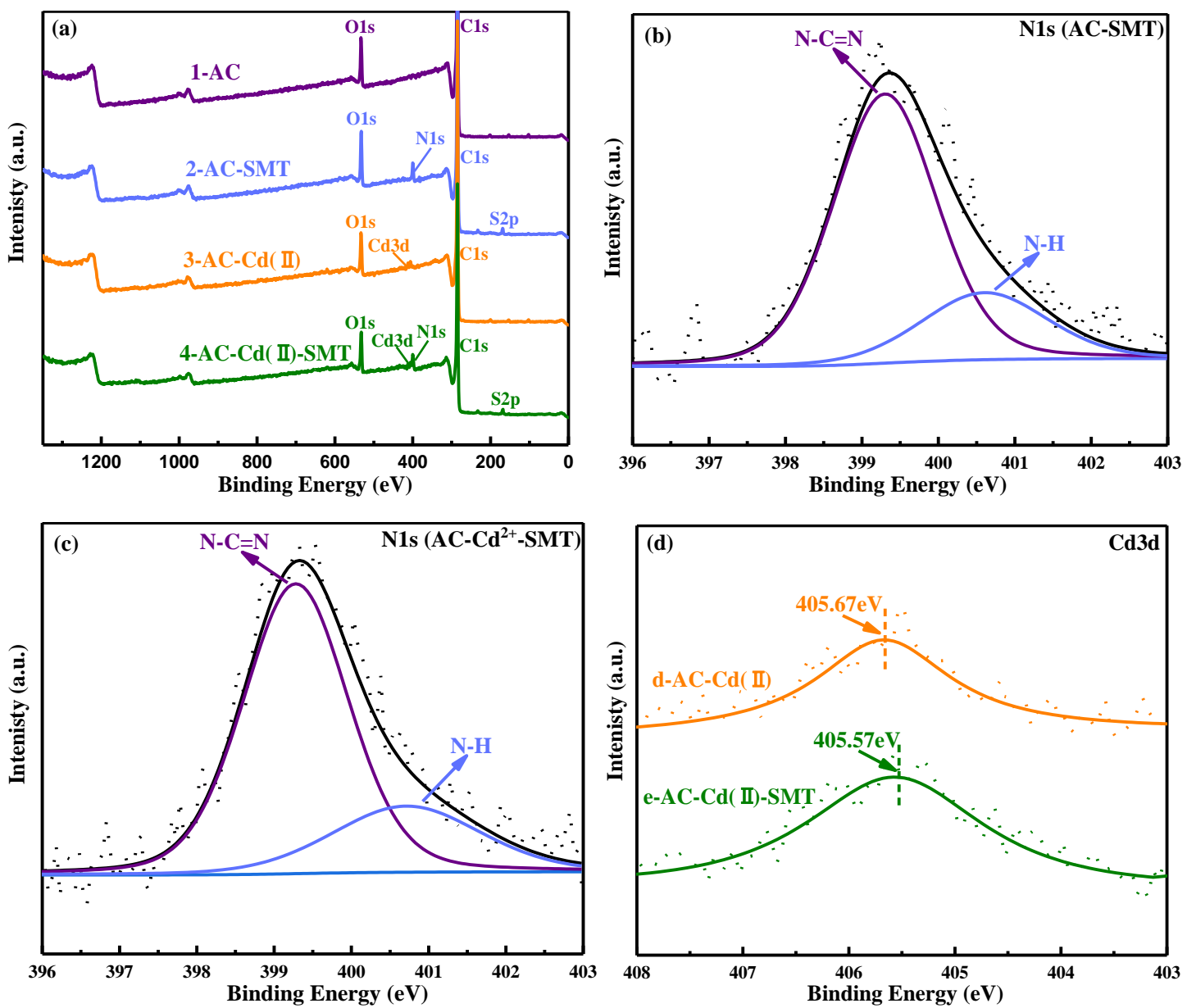

Fig. 6. (a) Full-scan XPS profiles of AC before adsorption (1), SMT-adsorbed AC (2), Cd( II)-adsorbed AC (3), and

SMT/Cd( I)-adsorbed AC (4). XPS N1s deconvolution peak resolution of (b) SMT-adsorbed AC; (c) 
C), is the characteristic scattering peak of graphite, whereas the second peak at $1350 \mathrm{~cm}^{-1}$ (D peak, $\mathrm{sp}^{3} \mathrm{C}$ ) is due to lattice defects, disorder, and low-symmetry sites in the carbon structure of graphite[59]. The Raman intensities are related to the structural order of the carbon sheets. The ID/IG ratio (where ID and IG are the intensities of the D and G peaks, respectively) is sensitive to the graphitization degree, which is the parameter used to measure the defect density of activated carbon[으. Therefore, the graphitization degree of a carbon material can be evaluated using the $R=\mathrm{ID} / \mathrm{IG}$ parameter. A smaller $R$ value corresponds to a higher degree of graphitization[61]. The ID and IG values are obtained by calculating the peak areas of peak D and peak $\mathrm{G}$, and the relative intensity ratio of ID/IG is obtained[들.The $R$ values of the four Raman spectra were $2.06(\mathrm{AC}), 2.20\left({\left.\mathrm{AC}-\mathrm{Cd}^{2+}\right)}^{2+} 1.98(\mathrm{AC}-\mathrm{SMT})\right.$, and $1.936\left(\mathrm{AC}-\mathrm{SMT} / \mathrm{Cd}^{2+}\right)$. The $\mathrm{D}$ band at $1350 \mathrm{~cm}^{-1}$ is a defect-induced feature, which reflects the imperfect crystal structure of carbon. Compared with AC, the ID/IG value of the AC-Cd ${ }^{2+}$ system increased from 2.06 to 2.2, which indicates that more structural defects were formed on $\mathrm{Cd}^{2+}$-doped $\mathrm{AC}[\underline{63}]$, resulting in a more disordered $\mathrm{AC}$ structure. However, the ID/IG values of SMT and SMT/ $\mathrm{Cd}^{2+}$ decreased from 2.06 to 1.98 and 1.936, respectively, indicating a reduced defect density and higher graphitization degree of carbon. This type of activated carbon substrate will provide more binding sites for the adsorption process; in other words, the high degree of graphitization can

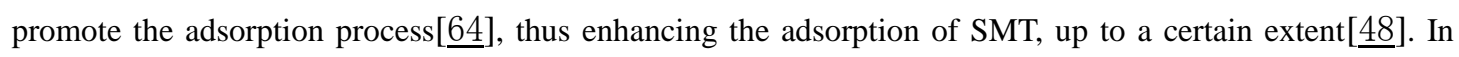
agreement with the above FTIR analysis, with the enhanced SMT adsorption, the formation of the $\mathrm{Cd}^{2+}$-SMT complex on the activated carbon surface promoted the adsorption of SMT. 
at $5 \mathrm{ppm}$, corresponding to the hydrogen of the - $\mathrm{NH}$ - group connected to the pyrimidine ring; the third peak,

signal will thus disappear.

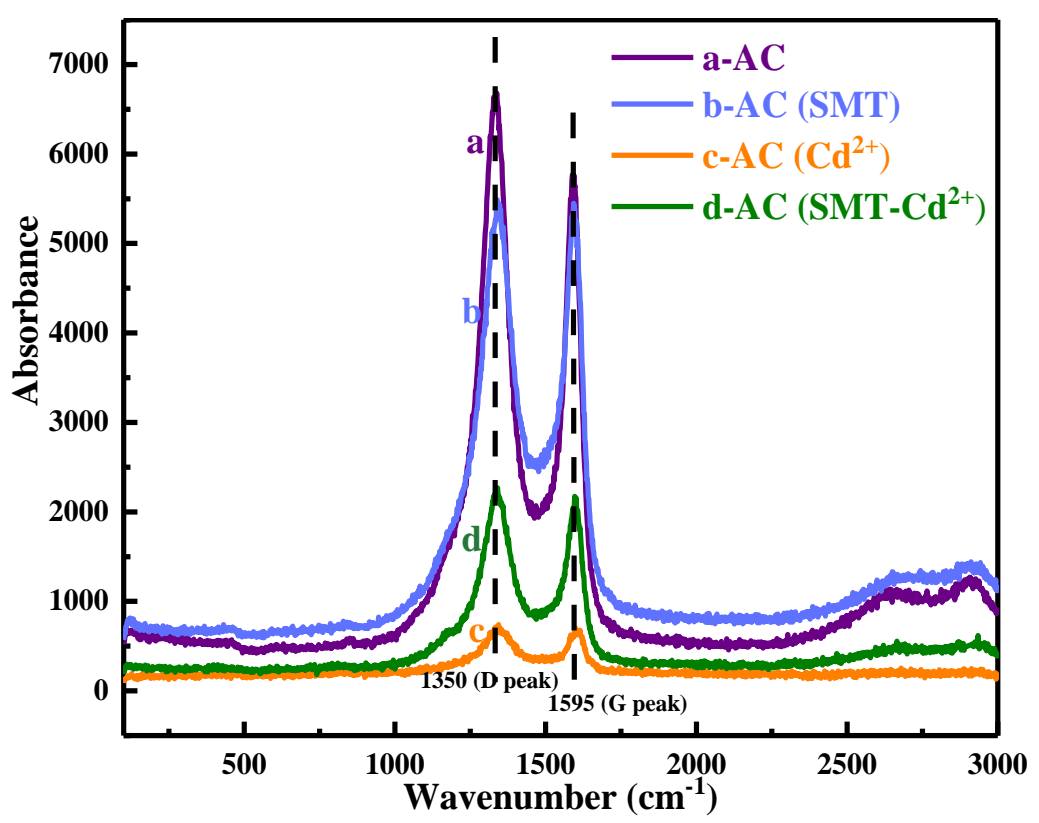

Fig. 7. Raman spectra of (a) AC before adsorption, (b) SMT-adsorbed AC, (c) Cd( II)-adsorbed AC, and (d) 


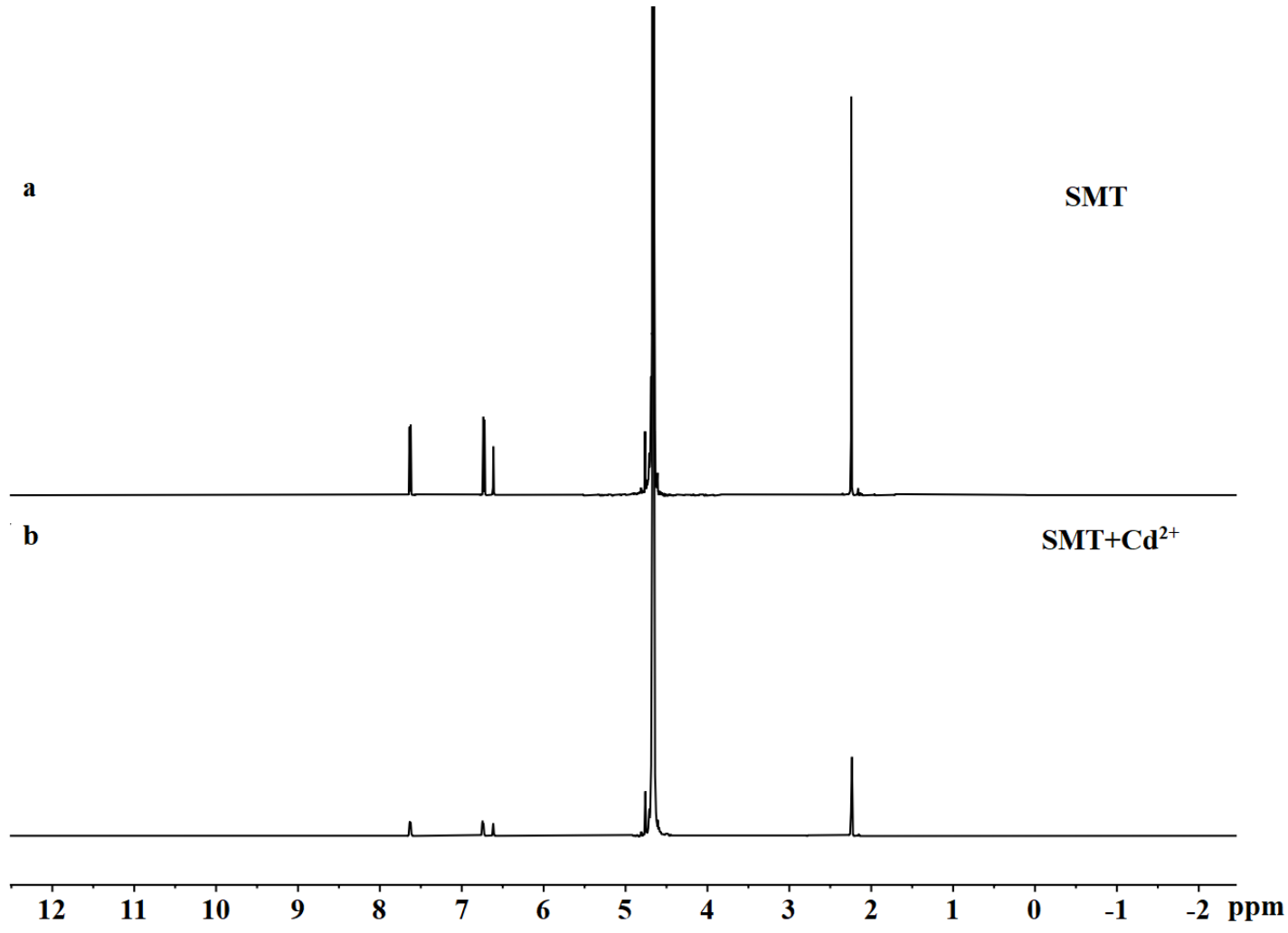

Fig. 8. ${ }^{1} \mathrm{H}$ NMR spectra of (a) SMT and (b) SMT-Cd( I).

\subsubsection{Correlation between SMT-Cd( I) complexation and adsorption capacity}

determine the possible relationship between the complexation of $\mathrm{Cd}^{2+}$ and SMT and their mutual adsorption. and the complexation ratio. The relationship between the concentration of the complex and the adsorption 


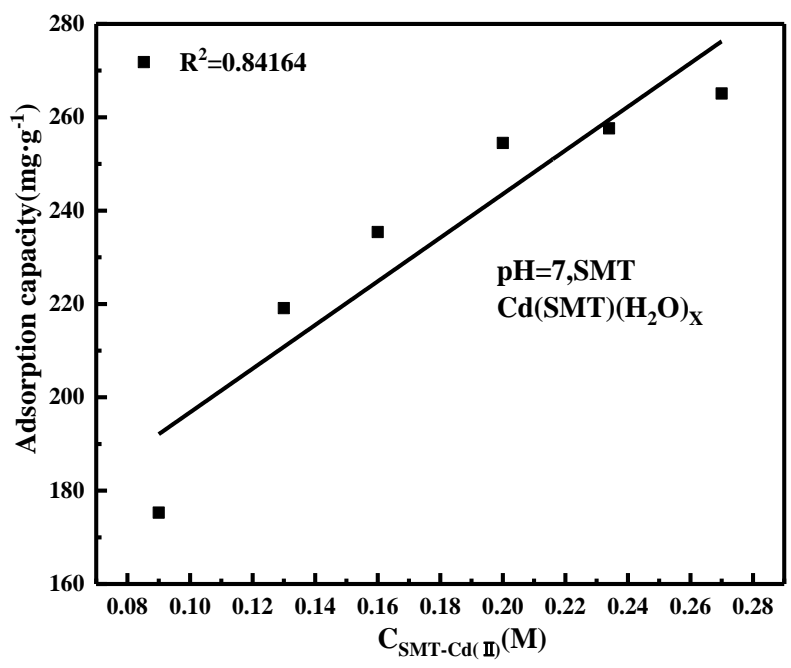

Fig. 9. Correlation between complexation ratio and adsorption capacity.

As shown in Fig. 10, SMT is adsorbed via a heterogeneous multilayer process, involving water and p-p stacking interactions between porous activated carbon and SMT[뭉. It is well known that p-p stacking interactions can explain the adsorption mechanism of aromatic substances on a layered activated carbon surface. Therefore, the molecular structure of SMT enables p-p stacking interactions between the benzene ring (p-electron acceptor) and the p-rich activated carbon adsorbent[50]. As an amphoteric molecule, SMT contains different charged or electron-rich groups. Therefore, electrostatic interactions may be established between the various functional groups of SMT and the corresponding surface structure of porous activated carbon[푸].

After cadmium ions are added to the system, they can form complexes with the SMT molecules and the functional groups on the AC surface. Upon formation of a ternary SMT-Cd ${ }^{2+}-\mathrm{AC}$ complex, $\mathrm{Cd}^{2+}$ promotes the adsorption of SMT on activated carbon, acting as a bridge (as shown by XPS) indirectly 
adsorption of SMT. As the adsorption of cadmium ions on activated carbon occurs in monolayer mode, when their concentration is increased above the monolayer (reaching the adsorption equilibrium), the $\mathrm{Cd}$ ions cannot further promote the adsorption of SMT, whose improvement is thus limited[25].

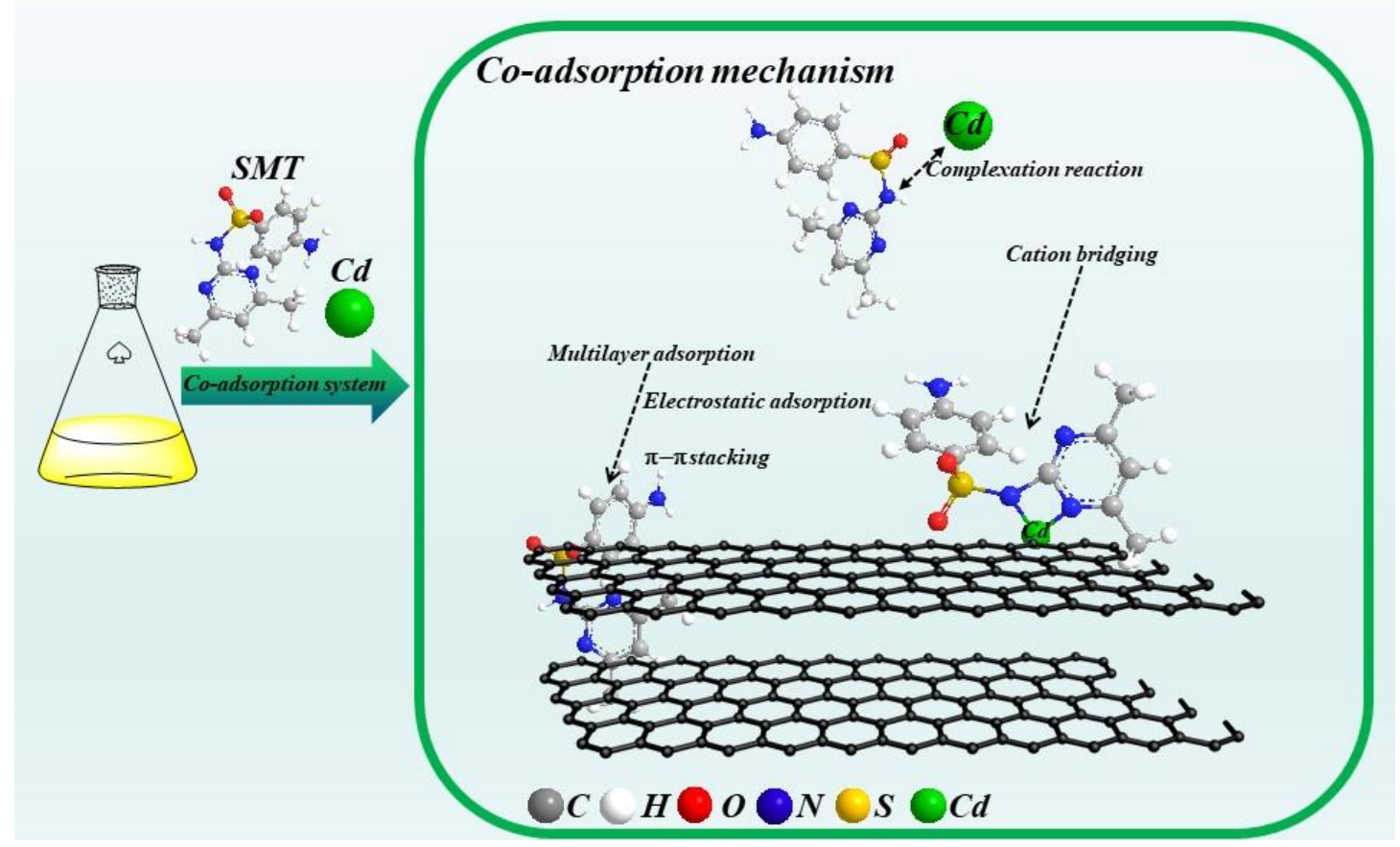

Fig. 10. Illustration of co-adsorption mechanism.

\section{Conclusion}

In this study, batch adsorption experiments were carried out in a single-pollutant $\left(\mathrm{SMT} / \mathrm{Cd}^{2+}\right)$ system under different adsorbent dosage, contact time, and temperature conditions. The experimental results show that the adsorption equilibrium of SMT is reached in approximately $12 \mathrm{~h}$, and the $\mathrm{pH}$ value of the solution affects the adsorption capacity of activated carbon. The adsorption by $\mathrm{AC}$ in alkaline conditions $(\mathrm{pH}=9)$ is 
weaker than that in acid conditions. The adsorption capacity of SMT decreases with increasing adsorbent dosage, while the removal rate increases.

In the SMT-Cd ${ }^{2+}$ co-adsorption system, as the cadmium ion concentration is increased, the synergistic effect of $\mathrm{Cd}^{2+}$ on the transport of SMT on activated carbon promotes its adsorption. The SMT adsorption data conform to the Freundlich isotherm model, indicating the multilayer heterogeneous adsorption behavior of SMT on AC. On the other hand, the adsorption of cadmium on AC can be described by the Langmuir isotherm model, which suggests monolayer adsorption; therefore, no further promotion of SMT adsorption can be achieved when the concentration of cadmium ions is increased above the monolayer coverage.

The characterization analysis showed the formation of a ternary AC-Cd ${ }^{2+}-\mathrm{SMT}$ complex at a certain concentration of $\mathrm{Cd}^{2+}$. Cadmium act as a bridge indirectly connecting SMT with activated carbon, providing further adsorption sites for SMT molecules in water. At the same time, the presence of cadmium ions effectively reduces the electrostatic repulsion between SMT and activated carbon, thus promoting the adsorption of SMT. Moreover, under neutral conditions, the complexation of $\mathrm{Cd}^{2+}$ with SMT shows a strong correlation with the SMT adsorption amount $\left(R^{2}=0.84164\right)$. Overall, the present results show that the formation of a $\mathrm{Cd}^{2+}$-SMT complex has a significant effect on the adsorption of SMT. The current study also emphasizes that, for a better understanding of the ecological risks associated with a pollutant, any assessment of its environmental behavior should take into account the presence of other pollutants.

\section{Acknowledgements}

This study was funded by the National Natural Science Foundation of China (grant number 21367003), Guangxi Major Project Science and Technology (grant number AA17129001), and Guangxi Key Laboratory of Clean Pulp \& Papermaking and Pollution Control Open Foundation (grant number KF201724). 


\section{References}

[1] F. Zhao,F. Ju,K. Huang,Y. Mao,X.-X. Zhang,H. Ren, T. Zhang, Comprehensive insights into the key components of bacterial assemblages in pharmaceutical wastewater treatment plants. $\begin{array}{llllll}\text { Science of The Total Environment } 651 & \text { (2019) 2148-2157. }\end{array}$ https://doi.org/10.1016/j.scitotenv.2018.10.101

[2] J. Yan,J. Peng,L. Lai,F. Ji,Y. Zhang,B. Lai,Q. Chen,G. Yao,X. Chen, L. Song, Activation $\mathrm{CuFe} 2 \mathrm{O} 4$ by Hydroxylamine for Oxidation of Antibiotic Sulfamethoxazole. Environmental Science \& Technology 52 (2018) 14302-14310. 10.1021/acs.est.8b03340

[3] B. Lapo,H. Demey,J. Zapata,C. Romero, A. M. Sastre, Sorption of $\mathrm{Hg}(\mathrm{II})$ and $\mathrm{Pb}$ (II) Ions on Chitosan-Iron(III) from Aqueous Solutions: Single and Binary Systems. Polymers (Basel) 10 (2018). 10.3390/polym10040367

[4] L. Yuan,M. Yan,Z. Huang,K. He,G. Zeng,A. Chen,L. Hu,H. Li,M. Peng,T. Huang, G. Chen, Influences of $\mathrm{pH}$ and metal ions on the interactions of oxytetracycline onto nano-hydroxyapatite and their co-adsorption behavior in aqueous solution. Journal of Colloid and Interface Science 541 (2019) 101-113. https://doi.org/10.1016/j.jcis.2019.01.078

[5] Y. K. Lan,T. C. Chen,H. J. Tsai,H. C. Wu,J. H. Lin,I. K. Lin,J. F. Lee, C. S. Chen, Adsorption Behavior and Mechanism of Antibiotic Sulfamethoxazole on Carboxylic-Functionalized Carbon Nanofibers-Encapsulated Ni Magnetic Nanoparticles. Langmuir : the ACS journal of surfaces and colloids 32 (2016) 9530-9. 10.1021/acs.langmuir.6b02904

[6] B. Lapo,H. Demey,T. Carchi, A. M. J. P. Sastre, Antimony removal from water by a chitosan-Iron (III)[ChiFer (III)] biocomposite. 11 (2019) 351.

[7] X. He,Y. Xu,J. Chen,J. Ling,Y. Li,L. Huang,X. Zhou,L. Zheng, G. Xie, Evolution of corresponding resistance genes in the water of fish tanks with multiple stresses of antibiotics and heavy metals. Water Research 124 (2017) 39-48. https://doi.org/10.1016/j.watres.2017.07.048

[8] M. T. Hayat,M. Nauman,N. Nazir,S. Ali, N. Bangash, Chapter 7 - Environmental Hazards of Cadmium: Past, Present, and Future. In Cadmium Toxicity and Tolerance in Plants, Hasanuzzaman, M.; Prasad, M. N. V.; Fujita, M., Eds. Academic Press: 2019; pp 163-183.

[9] M. Adrees,S. Ali,M. Rizwan,M. Ibrahim,F. Abbas,M. Farid,M. Zia-ur-Rehman,M. K. Irshad, S. A. Bharwana, The effect of excess copper on growth and physiology of important food crops: a review. Environmental Science and Pollution Research 22 (2015) 8148-8162. 10.1007/s11356-015-4496-5

[10] R. R. Marquardt, S. Li, Antimicrobial resistance in livestock: advances and alternatives to antibiotics. Animal Frontiers 8 (2018) 30-37. 10.1093/af/vfy001

[11] S. Li,W. Shi,W. Liu,H. Li,W. Zhang,J. Hu,Y. Ke,W. Sun, J. Ni, A duodecennial national synthesis of antibiotics in China's major rivers and seas (2005-2016). Science of The Total Environment 615 (2018) 906-917. https://doi.org/10.1016/j.scitotenv.2017.09.328

[12] B. Huang,Y. Liu,B. Li,S. Liu,G. Zeng,Z. Zeng,X. Wang,Q. Ning,B. Zheng, C. Yang, Effect of $\mathrm{Cu}$ (II) ions on the enhancement of tetracycline adsorption by $\mathrm{Fe} 3 \mathrm{O} 4 @ \mathrm{SiO} 2-\mathrm{Chitosan} /$ graphene oxide nanocomposite. Carbohydrate Polymers $157 \quad$ (2017) 576-585. https://doi.org/10.1016/j.carbpol.2016.10.025

[13] Z. Yang,S. Jia,T. Zhang,N. Zhuo,Y. Dong,W. Yang, Y. Wang, How heavy metals impact on 
flocculation of combined pollution of heavy metals-antibiotics: A comparative study. Separation and Purification Technology 149 (2015) 398-406. https://doi.org/10.1016/j.seppur.2015.06.018

[14] F. Zhao,L. Yang,L. Chen,S. Li, L. Sun, Co-contamination of antibiotics and metals in peri-urban agricultural soils and source identification. Environmental Science and Pollution Research 25 (2018) 34063-34075. 10.1007/s11356-018-3350-y

[15] G. Liu,Z. Zhu,Y. Yang,Y. Sun,F. Yu, J. Ma, Sorption behavior and mechanism of hydrophilic organic chemicals to virgin and aged microplastics in freshwater and seawater. Environmental Pollution 246 (2019) 26-33. https://doi.org/10.1016/j.envpol.2018.11.100

[16] C. Sophia A, E. C. Lima, Removal of emerging contaminants from the environment by adsorption. Ecotoxicology and Environmental Safety $150 \quad$ (2018) 1-17. https://doi.org/10.1016/j.ecoenv.2017.12.026

[17] C. Vignaroli,S. Pasquaroli,B. Citterio,A. Di Cesare,G. Mangiaterra,D. Fattorini, F. Biavasco, Antibiotic and heavy metal resistance in enterococci from coastal marine sediment. Environmental Pollution 237 (2018) 406-413. https://doi.org/10.1016/j.envpol.2018.02.073

[18] H. Chen,B. Gao, H. Li, Removal of sulfamethoxazole and ciprofloxacin from aqueous solutions by graphene oxide. Journal of Hazardous Materials 282 (2015) 201-207. https://doi.org/10.1016/j.jhazmat.2014.03.063

[19] X. Peng,F. Hu,F. L. Y. Lam,Y. Wang,Z. Liu, H. Dai, Adsorption behavior and mechanisms of ciprofloxacin from aqueous solution by ordered mesoporous carbon and bamboo-based carbon. Journal of Colloid and Interface Science $460 \quad$ (2015) 349-360. https://doi.org/10.1016/j.jcis.2015.08.050

[20] C. Li,X. Zhu,H. He, Y. Fang,H. Dong,J. Lü,J. Li, Y. Li, Adsorption of two antibiotics on biochar prepared in air-containing atmosphere: Influence of biochar porosity and molecular size of antibiotics. Journal of Molecular Liquids $274 \quad$ (2019) 353-361. https://doi.org/10.1016/j.molliq.2018.10.142

[21] W. Zhan,L. Gao,X. Fu,S. H. Siyal,G. Sui, X. Yang, Green synthesis of amino-functionalized carbon nanotube-graphene hybrid aerogels for high performance heavy metal ions removal. Applied Surface $\quad$ Science $\quad 467-468 \quad$ (2019)

1122-1133. https://doi.org/10.1016/j.apsusc.2018.10.248

[22] S. Kabiri,D. N. H. Tran,S. Azari, D. Losic, Graphene-Diatom Silica Aerogels for Efficient Removal of Mercury Ions from Water. ACS Applied Materials \& Interfaces 7 (2015) 11815-11823. 10.1021/acsami.5b01159

[23] X. He,L. Cheng,Y. Wang,J. Zhao,W. Zhang, C. Lu, Aerogels from quaternary ammonium-functionalized cellulose nanofibers for rapid removal of $\mathrm{Cr}(\mathrm{VI})$ from water. Carbohydrate Polymers 111 (2014) 683-687. https://doi.org/10.1016/j.carbpol.2014.05.020

[24] T. T. P. N. X. Trinh,D. T. Quang,T. H. Tu,N. M. Dat,V. N. P. Linh,L. Van Cuong,L. T. T. Nghia,T. T. Loan,P. T. Hang,N. T. L. Phuong,M. T. Phong,H. M. Nam, N. H. Hieu, Fabrication, characterization, and adsorption capacity for cadmium ions of graphene aerogels. Synthetic Metals 247 (2019) 116-123. https://doi.org/10.1016/j.synthmet.2018.11.020

[25] F. Yu,Y. Li,G. Huang,C. Yang,C. Chen,T. Zhou,Y. Zhao, J. Ma, Adsorption behavior of the antibiotic levofloxacin on microplastics in the presence of different heavy metals in an aqueous solution. Chemosphere 260 (2020) 127650. https://doi.org/10.1016/j.chemosphere.2020.127650

[26] N. Yao,C. Li,J. Yu,Q. Xu,S. Wei,Z. Tian,Z. Yang,W. Yang, J. Shen, Insight into adsorption of combined antibiotic-heavy metal contaminants on graphene oxide in water. Separation and 
Purification Technology 236 (2020) 116278. https://doi.org/10.1016/j.seppur.2019.116278

[27] X. Gu,Y. Tan,F. Tong, C. Gu, Surface complexation modeling of coadsorption of antibiotic ciprofloxacin and $\mathrm{Cu}(\mathrm{II})$ and onto goethite surfaces. Chemical Engineering Journal 269 (2015) 113-120. https://doi.org/10.1016/j.cej.2014.12.114

[28] N. Zhao,C. Zhao,Y. Lv,W. Zhang,Y. Du,Z. Hao, J. Zhang, Adsorption and coadsorption mechanisms of $\mathrm{Cr}(\mathrm{VI})$ and organic contaminants on H3PO4 treated biochar. Chemosphere 186 (2017) 422-429. https://doi.org/10.1016/j.chemosphere.2017.08.016

[29] Y. Sun,Q. Yue,B. Gao,Y. Gao,X. Xu,Q. Li, Y. Wang, Adsorption and cosorption of ciprofloxacin and $\mathrm{Ni}(\mathrm{II})$ on activated carbon-mechanism study. Journal of the Taiwan Institute of Chemical Engineers 45 (2014) 681-688. https://doi.org/10.1016/j.jtice.2013.05.013

[30] A. Frei,J. Zuegg,A. G. Elliott,M. Baker,S. Braese,C. Brown,F. Chen,C. G. Dowson,G. Dujardin,N. Jung,A. P. King,A. M. Mansour,M. Massi,J. Moat,H. A. Mohamed,A. K. Renfrew,P. J. Rutledge,P. J. Sadler,M. H. Todd,C. E. Willans,J. J. Wilson,M. A. Cooper, M. A. T. Blaskovich, Metal complexes as a promising source for new antibiotics. Chemical Science 11 (2020) 2627-2639. 10.1039/C9SC06460E

[31] S. Iftekhar,D. L. Ramasamy,V. Srivastava,M. B. Asif, M. Sillanpää, Understanding the factors affecting the adsorption of Lanthanum using different adsorbents: A critical review. Chemosphere 204 (2018) 413-430. https://doi.org/10.1016/j.chemosphere.2018.04.053

[32] W. Chu,D. Yao,N. Gao,T. Bond, M. R. Templeton, The enhanced removal of carbonaceous and nitrogenous disinfection by-product precursors using integrated permanganate oxidation and powdered activated carbon adsorption pretreatment. Chemosphere 141 (2015) 1-6. https://doi.org/10.1016/j.chemosphere.2015.05.087

[33] J. Ma,Y. Xiong,X. Dai, F. Yu, Coadsorption behavior and mechanism of ciprofloxacin and Cu(II) on graphene hydrogel wetted surface. Chemical Engineering Journal 380 (2020) 122387. https://doi.org/10.1016/j.cej.2019.122387

[34] X. Zheng,Y. Zhou,X. Liu,X. Fu,H. Peng, S. Lv, Enhanced adsorption capacity of MgO/N-doped active carbon derived from sugarcane bagasse. Bioresource Technology 297 (2020) 122413. https://doi.org/10.1016/j.biortech.2019.122413

[35] E. Yousif,A. Majeed,K. Al-Sammarrae,N. Salih,J. Salimon, B. Abdullah, Metal complexes of Schiff base: Preparation, characterization and antibacterial activity. Arabian Journal of Chemistry 10 (2017) S1639-S1644. https://doi.org/10.1016/j.arabjc.2013.06.006

[36] G. Huschek,D. Hollmann,N. Kurowski,M. Kaupenjohann, H. Vereecken, Re-evaluation of the conformational structure of sulfadiazine species using NMR and ab initio DFT studies and its implication on sorption and degradation. Chemosphere 72 (2008) 1448-1454. https://doi.org/10.1016/j.chemosphere.2008.05.038

[37] X. Ma,C. Yang,Y. Jiang,X. Zhang,Q. Wang, Z. Dang, Desorption of heavy metals and tetracycline from goethite-coated sands: The role of complexation. Colloids and Surfaces A: Physicochemical and Engineering Aspects $573 \quad$ (2019) https://doi.org/10.1016/j.colsurfa.2019.04.050

[38] D. Huang,J. Wu,L. Wang,X. Liu,J. Meng,X. Tang,C. Tang, J. Xu, Novel insight into adsorption and co-adsorption of heavy metal ions and an organic pollutant by magnetic graphene nanomaterials in water. Chemical Engineering Journal 358 (2019) 1399-1409. https://doi.org/10.1016/j.cej.2018.10.138

[39] H. Qiu,C. Ling,R. Yuan,F. Liu, A. Li, Bridging effects behind the coadsorption of copper and 
sulfamethoxazole by a polyamine-modified resin. Chemical Engineering Journal 362 (2019) 422-429. https://doi.org/10.1016/j.cej.2019.01.043

[40] Y. Ma,K. Zhang,C. Li,T. Zhang, N. Gao, Oxidation of Sulfonamides in Aqueous Solution by UV-TiO2-Fe(VI). Biomed Res Int 2015 (2015) 973942. 10.1155/2015/973942

[41] I. Tlili,G. Caria,B. Ouddane,I. Ghorbel-Abid,R. Ternane,M. Trabelsi-Ayadi, S. Net, Simultaneous detection of antibiotics and other drug residues in the dissolved and particulate phases of water by an off-line SPE combined with on-line SPE-LC-MS/MS: Method development and application. Sci Total Environ 563-564 (2016) 424-33. 10.1016/j.scitotenv.2016.04.101

[42] T. Tang,C. Yang,L. Wang,X. Jiang,Z. Dang, W. Huang, Complexation of sulfamethazine with $\mathrm{Cd}(\mathrm{II})$ and $\mathrm{Pb}(\mathrm{II})$ : implication for co-adsorption of SMT and $\mathrm{Cd}(\mathrm{II})$ on goethite. Environmental Science and Pollution Research 25 (2018) 11576-11583. 10.1007/s11356-017-1026-7

[43] G. Xu,B. Zhang,X. Wang,N. Li,L. Liu,J.-M. Lin, R.-S. Zhao, Nitrogen-doped flower-like porous carbon nanostructures for fast removal of sulfamethazine from water. Environmental Pollution 255 (2019) 113229. https://doi.org/10.1016/j.envpol.2019.113229

[44] V. O. Shikuku,R. Zanella,C. O. Kowenje,F. F. Donato,N. M. G. Bandeira, O. D. Prestes, Single and binary adsorption of sulfonamide antibiotics onto iron-modified clay: linear and nonlinear isotherms, kinetics, thermodynamics, and mechanistic studies. Applied Water Science 8 (2018) 175. 10.1007/s13201-018-0825-4

[45] L.-Y. Gao,J.-H. Deng,G.-F. Huang,K. Li,K.-Z. Cai,Y. Liu, F. Huang, Relative distribution of $\mathrm{Cd} 2+$ adsorption mechanisms on biochars derived from rice straw and sewage sludge. Bioresource Technology 272 (2019) 114-122. https://doi.org/10.1016/j.biortech.2018.09.138

[46] X. Liu,Y. Wan,P. Liu,L. Zhao, W. Zou, Optimization of sulfamethazine sodium adsorption onto activated carbon-based Salix psammophila: investigation of adsorption behavior and mechanism. Journal of Dispersion Science and Technology $40 \quad$ (2019) 507-518. 10.1080/01932691.2018.1472011

[47] Z. Bai,Q. Yang, J. Wang, Catalytic ozonation of sulfamethazine antibiotics using Ce0.1Fe0.9OOH: Catalyst preparation and performance. Chemosphere 161 (2016) 174-180. 10.1016/j.chemosphere.2016.07.012

[48] Y. Liu,X. Liu,W. Dong,L. Zhang,Q. Kong, W. Wang, Efficient Adsorption of Sulfamethazine onto Modified Activated Carbon: A Plausible Adsorption Mechanism. Scientific reports 7 (2017) 12437. 10.1038/s41598-017-12805-6

[49] J. Ma,Y. Xiong,X. Dai, F. Yu, Coadsorption behavior and mechanism of ciprofloxacin and Cu(II) on graphene hydrogel wetted surface. Chemical Engineering Journal 380 (2020). 10.1016/j.cej.2019.122387

[50] Q. Chen,J. Zheng,J. Xu,Z. Dang, L. Zhang, Insights into sulfamethazine adsorption interfacial interaction mechanism on mesoporous cellulose biochar: Coupling DFT/FOT simulations with experiments. Chemical Engineering Journal $356 \quad$ (2019) 341-349. https://doi.org/10.1016/j.cej.2018.09.055

[51] J. Buschmann, L. Sigg, Antimony(III) Binding to Humic Substances: Influence of pH and Type of Humic Acid. Environmental science \& technology 38 (2004) 4535-41. 10.1021/es049901o

[52] G. Huschek,D. Hollmann,N. Kurowski,M. Kaupenjohann, H. Vereecken, Re-evaluation of the conformational structure of sulfadiazine species using NMR and ab initio DFT studies and its implication on sorption and degradation. Chemosphere 72 (2008) 1448-54. 
[53] B. Yang,X. Mao,L. Pi,Y. Wu,H. Ding, W. Zhang, Effect of $\mathrm{pH}$ on the adsorption and photocatalytic degradation of sulfadimidine in Vis/g-C(3)N(4) progress. Environmental science and pollution research international 24 (2017) 8658-8670. 10.1007/s11356-017-8448-0

[54] D. Wu,B. Pan,M. Wu,H. Peng,D. Zhang, B. Xing, Coadsorption of Cu and Sulfamethoxazole on Hydroxylized and Graphitized Carbon Nanotubes. The Science of the total environment 427-428 (2012) 247-52. 10.1016/j.scitotenv.2012.03.039

[55] H. Pašalić,A. J. Aquino,D. Tunega,G. Haberhauer,M. H. Gerzabek, H. Lischka, Cation- $\pi$ interactions in competition with cation microhydration: a theoretical study of alkali metal cation-pyrene complexes. Journal of molecular modeling $23 \quad$ (2017) 131. 10.1007/s00894-017-3302-3

[56] A. D. Fedorenko,L. N. Mazalov,I. M. Oglezneva,E. Y. Fursova, V. I. Ovcharenko, An X-ray photoelectron study of the electronic structure of $\mathrm{Cu}(\mathrm{II})$ complexes with dia- and paramagnetic derivatives of 2-imidazoline. Journal of Structural Chemistry 57 (2017) 1121-1126. $10.1134 / \mathrm{s} 0022476616060093$

[57] X. Meng,L. Wang,L. Chen,M. Xu,N. Liu,J. Zhang,Y. Yang, M. Wei, Charge-separated metal-couple-site in NiZn alloy catalysts towards furfural hydrodeoxygenation reaction. Journal of Catalysis 392 (2020) 69-79. https://doi.org/10.1016/j.jcat.2020.10.003

[58] H. Pinto,V. Haapasilta,M. Lokhandwala,S. Öberg, A. S. Foster, Adsorption and migration of single metal atoms on the calcite (10.4) surface. Journal of physics. Condensed matter : an Institute of Physics journal 29 (2017) 135001. 10.1088/1361-648X/aa5bd9

[59] V. Georgakilas,J. A. Perman,J. Tucek, R. Zboril, Broad Family of Carbon Nanoallotropes: Classification, Chemistry, and Applications of Fullerenes, Carbon Dots, Nanotubes, Graphene, Nanodiamonds, and Combined Superstructures. Chemical Reviews 115 (2015) 4744-4822. $10.1021 / \mathrm{cr} 500304 \mathrm{f}$

[60] Q. Yan,J. Li,X. Zhang,E. B. Hassan,C. Wang,J. Zhang, Z. Cai, Catalytic graphitization of kraft lignin to graphene-based structures with four different transitional metals. Journal of Nanoparticle Research 20 (2018) 223. 10.1007/s11051-018-4317-0

[61] Z. Li,B. Li,C. Yang,S. Lin,Q. Pang, P. Shen, Controllable preparation of nitrogen-doped graphitized carbon from molecular precursor as non-metal oxygen evolution reaction $\begin{array}{lllllll}\text { electrocatalyst. } & \text { Applied } & \text { Surface } & \text { Science } & 491 & \text { (2019) }\end{array}$ https://doi.org/10.1016/j.apsusc.2019.06.183

[62] Y. Liu,X. Liu,G. Zhang,T. Ma,T. Du,Y. Yang,S. Lu, W. Wang, Adsorptive removal of sulfamethazine and sulfamethoxazole from aqueous solution by hexadecyl trimethyl ammonium bromide modified activated carbon. Colloids and Surfaces A: Physicochemical and Engineering Aspects 564 (2019) 131-141. 10.1016/j.colsurfa.2018.12.041

[63] H. Huang,X. Wang,Y. Sheng,C. Chen,X. Zou,X. Shang, X. J. R. a. Lu, Nitrogen-doped graphene-activated metallic nanoparticle-incorporated ordered mesoporous carbon nanocomposites for the hydrogenation of nitroarenes. 8 (2018) 8898-8909.

[64] W. Sun,J. Bai,C. Li, J. Liu, Effect of graphitization degree of electrospinning carbon fiber on catalytic oxidation of styrene and electrochemical properties. Chemical Physics Letters 715 (2019) 299-309. https://doi.org/10.1016/j.cplett.2018.11.055

[65] P. Hobza, Z. Havlas, Blue-Shifting Hydrogen Bonds. Chemical Reviews 100 (2000) 4253-4264. $10.1021 / \mathrm{cr} 990050 \mathrm{q}$ 
[66] A. Mansour, DFT studies, spectral and biological activity evaluation of binary and ternary sulfamethazine $\mathrm{Fe}(\mathrm{III})$ complexes. Journal of Coordination Chemistry 67 (2014). 10.1080/00958972.2014.951345

[67] A. Ashraf,W. A. Siddiqui,J. Akbar,G. Mustafa,H. Krautscheid,N. Ullah,B. Mirza,F. Sher,M. Hanif, C. G. Hartinger, Metal complexes of benzimidazole derived sulfonamide: Synthesis, molecular structures and antimicrobial activity. Inorganica Chimica Acta 443 (2016) 179-185. https://doi.org/10.1016/j.ica.2015.12.031

[68] E. J. Baran, V. T. Yilmaz, Metal complexes of saccharin. Coordination Chemistry Reviews 250 (2006) 1980-1999. https://doi.org/10.1016/j.ccr.2005.11.021

[69] B. Kesimli, A. Topacli, Infrared studies on $\mathrm{Co}$ and $\mathrm{Cd}$ complexes of sulfamethoxazole. Spectrochimica Acta Part A: Molecular and Biomolecular Spectroscopy 57 (2001) 1031-1036. https://doi.org/10.1016/S1386-1425(00)00419-4

[70] M. Jia,F. Wang,Y. Bian,R. D. Stedtfeld,G. Liu,J. Yu, X. Jiang, Sorption of sulfamethazine to biochars as affected by dissolved organic matters of different origin. Bioresource Technology 248 (2018) 36-43. https://doi.org/10.1016/j.biortech.2017.08.082

[71] L. Zhang, S. Shen, Adsorption and catalytic degradation of sulfamethazine by mesoporous carbon loaded nano zero valent iron. Journal of Industrial and Engineering Chemistry 83 (2020) 123-135. https://doi.org/10.1016/j.jiec.2019.11.020 